\title{
Diabetes and hypertension screening in Zandspruit, Johannesburg 2012-2014
}

\author{
Paul Rheedera*, Tessy Muthembe $^{a}{ }^{(\mathbb{D}}$, Stefan Lawson $^{\mathrm{b}}$ and Julie Brink ${ }^{\mathrm{b}}$ \\ ${ }^{a}$ Department of Internal Medicine, University of Pretoria, Pretoria, South Africa \\ ${ }^{b}$ Project HOPE, Johannesburg, South Africa \\ *Corresponding author, email: prheeder@medic.up.ac.za
}

\begin{abstract}
Background: Hypertension (HT) and diabetes mellitus (DM) affect millions of individuals in South Africa and are among the leading causes of morbidity and mortality. Given the substantial public health and socio-economic burden South Africa faces due to the rising rates of chronic diseases, prevention strategies with community engagement may play a vital role in controlling these diseases and their associated sequelae.

Objectives and methods: Project HOPE, an implementing partner of the Lilly Non Communicable Disease (NCD) Partnership programme in South Africa, conducted screening days and home visits as part of a non-communicable disease awareness campaign in the Zandspruit suburb of western Johannesburg (lower income, informal settlement). Standardised assessment tools were used, which included glucose and blood pressure measurement.

Results: Of 7607 participants screened, $2773 / 7470$ (37.1\%) of those with blood pressure values could be classified as hypertensive with systolic blood pressure (BP) $\geq 140 \mathrm{mmHg}$ or diastolic BP $\geq 90 \mathrm{mmHg}$. Of the 7607 glucose screened individuals, 630 ( $8.3 \%$ ) had referable random capillary glucose levels $\geq 7.8 \mathrm{mmol} / \mathrm{l}$. There was a clear gradient of increased prevalence over age and body mass index (BMI) categories.

Conclusions: In this urban low-income suburb hypertension was common with hyperglycaemia less so. The number of participants returning to the clinic for confirmation of diagnoses was less than optimal and highlights the problem of communitybased screening.
\end{abstract}

Keywords: diabetes mellitus, hypertension, obesity, screening, South Africa

\section{Background}

According toWHOglobal healthestimates, chronicnon-communicable diseases (NCDs) are the second leading cause of death in Africa. In 2011, within the broad category of NCDs, stroke, hypertensive heart disease, diabetes mellitus (DM) and chronic kidney disease have been identified to account for $30 \%$ of the 9.5 million deaths, and $25.8 \%$ of the 675.4 million disability-adjusted life years (DALYs) recorded. ${ }^{1}$ South Africa is no exception to this global burden with a DM prevalence of 2.28 million cases of diabetes in South Africa in $2015 .{ }^{2}$

Data from the Study on Global Ageing and Adult Health (SAGE), conducted by the World Health Organization (WHO), which surveyed more than 35000 people aged 50 and over in South Africa, China, Ghana, India, Mexico and Russia, found that $78 \%$ of those who took part in South Africa had hypertension. ${ }^{3}$

Recommendations for screening for DM vary. Most if not all countries do not advocate mass or community-based screening for diabetes. For example, the American Diabetes Association's guideline recommends that testing to detect type 2 diabetes and prediabetes in asymptomatic people should be considered in adults of any age who are overweight or obese (BMI $\geq 25 \mathrm{~kg} / \mathrm{m}^{2}$ ) and who have one or more additional risk factors for diabetes. In those without these risk factors, testing should begin at age 45 years. They state that to test for diabetes or prediabetes, the A1C, FPG, or 2-hour 75-g OGTT are appropriate. ${ }^{4}$

The latest U.S. Preventive Services Task Force (USPSTF) recommendations for diabetes screening have been changed to now screening for abnormal blood glucose as part of cardiovascular risk assessment in adults aged 40 to 70 years who are overweight or obese. ${ }^{5}$
In Caucasian populations the FINDRISK questionnaire is currently the best available tool in clinical practice for predicting the risk of type 2 diabetes ${ }^{6}$ but it was shown not to be sufficient to detect undiagnosed diabetes or pre-diabetes in larger populations. ${ }^{7}$ Others have added $\mathrm{HbA} 1 \mathrm{c}$ to the FINDRISK score and found that having a score of 12 or greater with an $\mathrm{HbA} 1 \mathrm{c} 5.9 \%$ or greater identified 56 out of 65 people with diabetes ( $86 \%$ sensitivity). Diabetes was present in $1.2 \%$ of people with scores of less than $12 .{ }^{8}$

The Society of Endocrinology Metabolism and Diabetes of South Africa (SEMDSA) recommends that individuals at high risk or older/equal to 45 years of age be screened at intervals of at least 3 years. SEMDSA states that any of the fasting plasma glucose, the 2-hour oral glucose tolerance test (OGTT) or HbA1c be used, with the OGTT the preferred method in high-risk individuals. SEMDSA prefers screenings to take place in the health care setting as community-based screening may not ensure adequate follow-up of patients with positive screening tests. ${ }^{9}$

The test of choice for screening varies as mentioned, as do the cutoffs to be used. SEMDSA and the International Diabetes Federation (IDF) ${ }^{10}$ suggest that a random plasma glucose value of $\geq 5.6 \mathrm{mmol} / \mathrm{l}$ requires further evaluation. Fasting venous plasma glucose is the preferred method. The use of capillary measurements is contentious, with evidence that it has poor discrimination at an individual level. ${ }^{11}$ However, others have found it acceptable. ${ }^{12}$

The ADDITION Trial ${ }^{13}$ was a large multi-country study evaluating the effectiveness of primary care based screening followed by early treatment of those identified as having diabetes and it found no significant reduction in mortality. The final conclusion 
was that the study did not justify systematic screening in the community and that primary care teams should, rather, focus on risk factor detection and management.

Regarding hypertension, the U.S. Preventive Services Task Force (USPSTF) latest draft recommends screening for high blood pressure in adults 18 years and older. Ambulatory blood pressure monitoring is recommended to confirm high blood pressure before the diagnosis of hypertension, except in cases for which immediate initiation of therapy is necessary. ${ }^{14}$ The South African HT Guidelines do not mention screening per se. ${ }^{15}$

In South Africa, there are currently no studies available to establish whether systematic screening for diabetes and hypertension in asymptomatic adult patients followed by early treatment improves their health outcomes compared with a clinical diagnosis without prior screening. The South African Department of Health has responded to the emerging epidemic and issued its strategic plan in 2013. ${ }^{16}$ This strategy has three major components; these are to (1) prevent NCDs and promote health and wellness at population, community and individual levels; (2) improve control of NCDs through health systems strengthening and reform; (3) monitor NCDs and their main risk factors and conduct innovative research. This document also mentions that successful implementation of the strategy for prevention and control of chronic conditions is dependent on the primary healthcare re-engineering process. This includes a renewed focus on community-oriented primary care with primary health care outreach teams. What role screening will play in this strategy is unclear.

The National Department of Health has proposed an NCD screening and awareness campaign for South Africa. Various settings will contribute data to give a picture of the NCD burden in the country.

The pharmaceutical company Lilly has embarked on a Non Communicable Disease Program ${ }^{17}$ together with partners Project $\mathrm{HOPE}$, the Donald Woods Foundation and the University of Pretoria. The aim of this programme is to improve non-communicable disease detection and management in neglected urban and rural settings (such as urban informal settlements and the rural Eastern Cape). Between 2012 and 2015 Project HOPE initiated screening and awareness activities in the community of Zandspruit, Johannesburg. This paper reports on the results of body mass index, glucose and blood pressure measurement in this community.

\section{Methods \\ Setting}

Zandspruit is a suburb of western Johannesburg situated in Gauteng province and represents living conditions for the urban poor with mostly informal housing. Zandspruit is one of the oldest, least developed and fastest growing informal settlements in the Johannesburg area and is home to an estimated 200000 residents. The Helen Joseph Hospital is the referral hospital $30 \mathrm{~km}$ from the clinic. Project HOPE manages the HOPE centre in this community to address the challenge of NCDs in this setting. ${ }^{18}$

\section{Study design and participant selection}

This was a cross-sectional study using data collected from nonrandom screening activities in the community.
Participants 18 years and older were included in this analysis.

\section{First cycle}

(a) Period: From June 2012 until June 2013, Project HOPE conducted 44 mobile screening days, including 6 door-todoor week-long campaigns (one five-day campaign per month from January to June 2013). Door-to-door campaigns and screening gazebos covered all major entry and exit points of the community to ensure visibility in Zandspruit.

(b) Procedures: The door-to-door campaign and community screening activities utilised the skills of locally trained volunteers and nurses from a local nursing college (Empilweni Nursing College). Teams of two to four volunteers split up to perform door-to-door screenings. On each screening day patients signed informed consents and were given a random capillary glucose (RCG) test and two blood pressure (BP) tests (left and right arm).

(c) Referral. Those who had a systolic BP $>120 \mathrm{mmHg}$ and/or a diastolic BP $>80 \mathrm{mmHg}$ or an RCG result $>5.6 \mathrm{mmol} / \mathrm{L}$ were referred to the HOPE Centre clinic where they were to receive a follow-up screening to confirm diagnosis.

\section{Second cycle}

(a) Period: From January to July 2014.

(b) Procedures: Community screening activities were conducted by locally trained volunteers and skilled community health workers from a local nursing college (Rose Star Nursing School).

Screenings were conducted by setting up gazebos in busy areas within the community instead of door-to-door. This ensured that participants were able to sit comfortably while their glucose and blood pressure tests were being performed and while they received counselling on the results of the tests. Project HOPE performed one three-day campaign per month which was scheduled on Wednesday, Thursday, Friday or Thursday, Friday, Saturday in order to make screening those who were working more feasible (we found that most residents of the community who work were more often home and available for screenings on Friday or Saturday). Project HOPE also held one 'third Friday' screening per month during which we set up screening gazebos in the same place on each third Friday of the month so that the community would know we would be there on a consistent basis, in order for them to refer family or friends for screenings.

(c) Referral: Participants who were classified as 'high-risk' (systolic $\mathrm{BP}>160 \mathrm{mmHg}$ or diastolic $\mathrm{BP}>100 \mathrm{mmHg}$ orRCG $>11 \mathrm{mmol} / \mathrm{L}$ ) were given appointments at the clinic to visit as soon as possible (unlike the previous cycle where referral was done at much lower levels of glucose and blood pressure). If a patient had not completed a follow-up appointment at the clinic within one week, a home visit with the patient was scheduled. Repeat SMS, phone call and home visit was done weekly until the patient was scheduled for an appointment. 
Participants with systolic BP $\geq 140 \mathrm{mmHg}$ or diastolic $\mathrm{BP} \geq 90 \mathrm{mmHg}$ or RCG $\geq 7 \mathrm{mmol} / \mathrm{l}$ were contacted by SMS and phone within one week of the date the patient was screened. Repeat SMS and phone call were done weekly until the patient was either scheduled for an appointment or the patient had been contacted three times.

\section{Anthropometric assessment}

Each trained fieldworker followed standardised and internationally accepted methodology. Each fieldworker was equipped with a Salter $^{\circledast}$ (Salter Housewares, Tonbridge, Kent, UK) mechanical bathroom scale to take a subject's weight, a portable high-measure rod to measure the height, a flexible tape measure that was used for waist circumference and a Homemed Glucocheck ${ }^{\circledR}$ (Homemed (Pty), Pretoria, South Africa) point-of-care device to check random blood glucose. The blood pressure was measured with an Omron ${ }^{\circledR}$ M5-I electronic device (Omron Healthcare, Hoofddorp, the Netherlands).

Participants at risk of having diabetes and hypertension based on their elevated blood results and blood pressure were given health education on how to modify their lifestyle.

\section{Data management and analysis}

Data were entered in Epidata version 3.1 and analysed in STATA ${ }^{\oplus}$ version 13 (StataCorp LP, College Station, TX, USA). Data were summariaed with descriptive statistics. Glucose categories were classified using cut points recommended by the SEDMSA diabetes guideline ${ }^{9}$ for diabetes testing and not the cut points used for screening. This was done in order to make comparisons with other studies possible. Age categories were in accordance with the SANHANES-1 study. ${ }^{19}$ BMI categories were done according to World Health Organization definitions. ${ }^{20}$ Each participant had two values of blood pressure; the highest systolic $\mathrm{BP}$ value was the one taken in our analysis. Blood pressure categories were classified using the SA hypertension guidelines. ${ }^{17}$

\section{Ethical guidelines}

Ethical approval was granted by the University of Pretoria's Faculty of Health Sciences Ethics Committee (protocol number: 247/2011). Participants signed informed consent.

\section{Results}

In the study the mean BMI of males $\left(24.9 \mathrm{~kg} / \mathrm{m}^{2}\right)$ and the RCG $(5.9 \mathrm{mmol} / \mathrm{l})$ were both found to be significantly lower than those of females $\left(28.1 \mathrm{~kg} / \mathrm{m}^{2}\right.$ and $6.1 \mathrm{mmol} / /$ respectively). The mean systolic BP for males (134.3 mmHg) was significantly higher than for females $(129.9 \mathrm{mmHg}$ ) but diastolic BP did not differ by gender. Among the screened patients, 41 patients had glucose values missing, 176 had systolic BP missing and 178 had diastolic BP missing (see Table 1).

Table 1: Characteristics of people screened for diabetes and hypertension in Zandspruit

\begin{tabular}{lccc}
\hline Factor & $\begin{array}{c}\text { Male, mean } \\
(\text { SD })\end{array}$ & Female, mean (SD) & $\boldsymbol{p}$ \\
\hline Age (years) & $34.4(11.8)$ & $34.9(12.5)$ & 0.081 \\
BMl $\left(\mathrm{kg} / \mathrm{m}^{2}\right)$ & $24.9(5.2)$ & $28.1(6.6)$ & $<0.001$ \\
RCG $(\mathrm{mmol} / \mathrm{l})$ & $5.9(2.0)$ & $6.1(2.4)$ & $<0.001$ \\
Systolic BP $(\mathrm{mmHg})$ & $134.3(19.3)$ & $129.9(20.6)$ & $<0.001$ \\
Diastolic BP $(\mathrm{mmHg})$ & $82.7(13.4)$ & $82.8(13.7)$ & 0.759 \\
Total & 3558 & 4049 & \\
\hline
\end{tabular}

Notes: $\mathrm{BP}=$ blood pressure, $\mathrm{SD}=$ standard deviation, $\mathrm{RCG}=$ random capillary glucose, $\mathrm{BMI}=$ body mass index.
From June 2012 to June 2013, half of the 6246 screened patients (51.4\%) were referred to the HOPE Centre clinic based on a random capillary glucose (RCG) greater than $5.6 \mathrm{mmol} / \mathrm{l}$. However, if the cut-off point for RCG was taken from $7 \mathrm{mmol} / \mathrm{l}$ as in 2014 , only $17.6 \%$ would have been referred to the clinic. Similarly, of the 6072 screened for hypertension from June 2012 to June 2013, 75.4\% were also referred based on their systolic BP $>120 \mathrm{mmHg}$ or diastolic BP $>80 \mathrm{mmHg}$, whereas if the standard categories for hypertension ${ }^{8}$ were applied during the screening only $17.8 \%$ would have been referred as having a high systolic BP > $140 \mathrm{mmHg}$ or diastolic BP > $90 \mathrm{mmHg}$.

From January 2014, the screening methodology was modified to a clinic referral of patients who had RCG $>7 \mathrm{mmol} / \mathrm{l}$ and those who had systolic BP $>140 \mathrm{mmHg}$ or diastolic BP $>90 \mathrm{mmHg}$. Of the 1402 screened participants $11.8 \%$ were referred for high RCG and $36 \%$ were also referred for possible hypertension. If previous cut-offs were still taken into consideration, $47.1 \%$ and $79.1 \%$ of the total screened participants would have been referred to the clinic based on their RCG and BP values respectively. From data collected in 2014, 33\% of screened referable patients attended follow-up at the clinic (210/639).

Combining the two time periods our results show that $37.1 \%$ of the 7470 screened individuals could be classified as hypertensive with systolic $B P \geq 140 \mathrm{mmHg}$ or diastolic $B P \geq 90 \mathrm{mmHg}$. Likewise $8.3 \%$ of the 7607 screened individuals had referable RCG levels $\geq 7.8 \mathrm{mmol} / \mathrm{l}$ (see Table 2 ).

Significant increases in both glucose and BP were found as age increased ( $p<0.001$ for trend). Similarly the percentage of participants with hypertension increased as their BMI increased (Grade $3 \mathrm{HT}$ increased from $3.1 \%$ to $8.7 \%$, $p$ for trend $<0.001)$. The same trend was noted for BMI and high RCG whereby the percentage of participants having diabetes doubled from $1.0 \%$ to $3.6 \%$ ( $p$ for trend $<0.001$ ) (see Tables 3-5).

In Figure 2 we demonstrate the overlap between subjects with hyperglycaemia (RCG $\geq 7.8 \mathrm{mmo} / \mathrm{l}$ ), hypertension (Stage 1 to 3 ) and obesity (BMI $\geq 30$ ), with 230 records excluded where there was information missing in a category. Some $2 \%$ of screened patients had overlap between all three conditions and $10 \%$ had overlap between obesity and hypertension; $46 \%$ of screened patients had none of the three conditions.

Table 2: Distribution of random capillary glucose (RCG) and blood pressure (BP)

\begin{tabular}{lc}
\hline Factor & Screened patients, $\boldsymbol{n}(\%)$ \\
\hline Random capillary glucose $(\mathrm{mmol} / \mathrm{l})$ & $6977(91.7)$ \\
$<7.8$ & $468(6.2)$ \\
$7.8-11$ & $162(2.1)$ \\
$\geq 11.1$ & 7607 \\
\hline Total & \\
Blood pressure $(\mathrm{mmHg})$ & $3199(42.8)$ \\
\hline Normal BP $(<130$ and $<85)$ & $1498(20.0)$ \\
\hline High normal BP $(130-139$ or $85-89)$ & $1731(23.2)$ \\
Stage 1 mild BP $(140-159$ or $90-99)$ & $663(8.9)$ \\
\hline Stage 2 moderate $\mathrm{HT}(160-179$ or $100-109)$ & $379(5.0)$ \\
\hline Stage 3 severe HT $(180$ plus or 110 plus) & 7470 \\
\hline Total & \\
\hline
\end{tabular}


Table 3: Distribution of BP and RCG among males and females, $n$ (\%)

\begin{tabular}{|c|c|c|c|c|c|c|c|}
\hline \multirow[t]{2}{*}{ Patients } & \multicolumn{6}{|c|}{ Blood pressure $(\mathrm{mmHg})$} & \multirow[b]{2}{*}{ Total } \\
\hline & Normal BP & High normal & Stage 1 mild HT & Stage 2 moderate HT & Stage 3 severe HT & & \\
\hline Male & $1319(37.7)$ & $772(22.0)$ & $911(26.0)$ & $324(9.3)$ & $175(5.0)$ & & 3501 \\
\hline Female & $1876(47.5)$ & $717(18.2)$ & 814 (20.6) & $338(8.6)$ & $204(5.2)$ & & 3949 \\
\hline Total & 3195 (42.9) & $1489(20.0)$ & $1725(23,2)$ & $662(8.9)$ & $379(5.0)$ & & 7450 \\
\hline \multirow[t]{2}{*}{ Patients } & & \multicolumn{4}{|c|}{ Random capillary glucose (mmol/l) } & \multirow{2}{*}{\multicolumn{2}{|c|}{ Total }} \\
\hline & & $<7.8$ & $7.8-11$ & & & & \\
\hline Male & & $3273(92.4)$ & $214(6.0)$ & & & 3544 & \\
\hline Female & & $3684(91.2)$ & $253(6.3)$ & & & 4041 & \\
\hline Total & & 6957(91.7) & $467(6.7)$ & & & 7585 & \\
\hline
\end{tabular}

Notes: Pearson's chi-square (4) $=80.4565 ; p<0.001$.

Pearson's chi-square $(2)=8.73 ; p=0.013$.

Table 4: Distribution of BP across age and BMI categories, $n$ (\%)

\begin{tabular}{|c|c|c|c|c|c|c|}
\hline \multicolumn{6}{|c|}{ Blood pressure $(\mathrm{mmHg})$} & \multirow[b]{2}{*}{ Total } \\
\hline Age (years) & Normal & High normal & Stage 1 mild HT & Stage 2 moderate HT & Stage 3 severe HT & \\
\hline $18-24$ & $920(56.0)$ & $332(20.2)$ & $298(18.1)$ & $64(4.0)$ & $29(1.8)$ & 1643 \\
\hline $25-34$ & $1255(45.3)$ & $650(23.5)$ & $591(21.3)$ & $198(7.2)$ & $75(2.7)$ & 2769 \\
\hline $35-44$ & $578(39.8)$ & $253(17.4)$ & $374(25.8)$ & $152(10.5)$ & $95(6.5)$ & 1452 \\
\hline $45-54$ & $253(28.5)$ & $151(17.0)$ & $255(28.7)$ & $136(15.3)$ & $94(10.6)$ & 889 \\
\hline $55-64$ & $109(23.9)$ & $62(13.6)$ & $149(32.7)$ & 85 (18.6) & $51(11.2)$ & 456 \\
\hline$\geq 65$ & $30(21.0)$ & $20(14.0)$ & $42(29.4)$ & $22(15.4)$ & $29(20.3)$ & 143 \\
\hline Total & $3145(42.8)$ & $1468(20.0)$ & $1709(23.3)$ & $657(8.9)$ & $373(5.0)$ & 7352 \\
\hline \multicolumn{6}{|c|}{ Blood pressure (mmHg) } & \multirow[b]{2}{*}{ Total } \\
\hline$\left(\mathrm{BMI}\left(\mathrm{kg} / \mathrm{m}^{2}\right)\right.$ & Normal & High normal & Stage 1 mild HT & Stage 2 moderate HT & Stage 3 severe HT & \\
\hline$<25$ & $1700(47.6)$ & $758(21.2)$ & $774(21.7)$ & $226(6.3)$ & $111(3.1)$ & 3569 \\
\hline $25-30$ & $827(41.7)$ & $411(20.8)$ & $457(23.0)$ & $183(9.2)$ & $103(5.2)$ & 1981 \\
\hline$\geq 30$ & $669(35.2)$ & $325(17.0)$ & $494(26.0)$ & $249(13.0)$ & 165 (8.7) & 1902 \\
\hline Total & 3196 (42.9) & $1494(20.0)$ & $1725(23.2)$ & 658 (8.8) & $379(5.0)$ & 7452 \\
\hline
\end{tabular}

Notes: Pearson's chi-square $(20)=645.3849 ; p<0.001$; test for trend $p<0.001$.

Pearson's chi-square $(8)=207.2296 ; p<0.001$; test for trend $p<0.001$.

Table 5: Distribution of RCG across age and BMI categories, $n$ (\%)

\begin{tabular}{|c|c|c|c|c|}
\hline \multirow[b]{2}{*}{ Age (years) } & \multicolumn{4}{|c|}{ Random capillary glucose (mmol/l) } \\
\hline & $<7.8$ & $7.8-11$ & $\geq 11.1$ & Total \\
\hline $18-24$ & $1595(95.7)$ & $61(3.7)$ & $10(0.6)$ & 1666 \\
\hline $25-34$ & 2624 (93.6) & $143(5.1)$ & $36(1.3)$ & 2803 \\
\hline $35-44$ & $1338(90.9)$ & $100(6.8)$ & $34(2.3)$ & 1472 \\
\hline $45-54$ & $810(87.6)$ & $88(9.5)$ & $27(2.9)$ & 925 \\
\hline $55-64$ & $383(81.7)$ & $49(10.5)$ & $37(7.8)$ & 469 \\
\hline$\geq 65$ & $116(77.3)$ & $21(14)$ & $13(8.7)$ & 150 \\
\hline Total & $6866(91.7)$ & $462(6.2)$ & $157(2.1)$ & 7485 \\
\hline
\end{tabular}

Notes: Pearson's chi-square (18) $=218.8789 ; p<0.001$; test for trend $p<0.001$. 


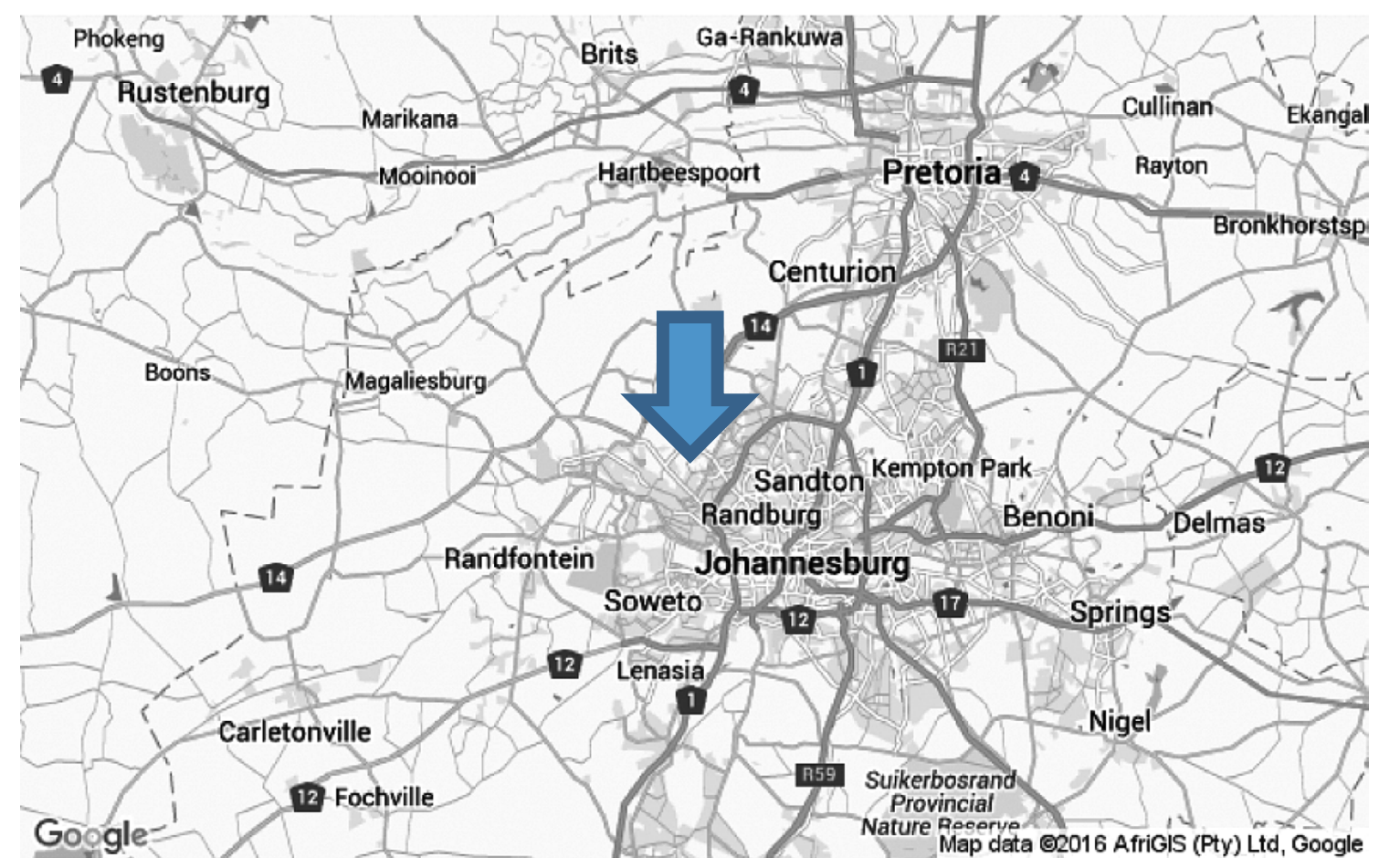

Figure 1: Map indicating location of Zandspruit.

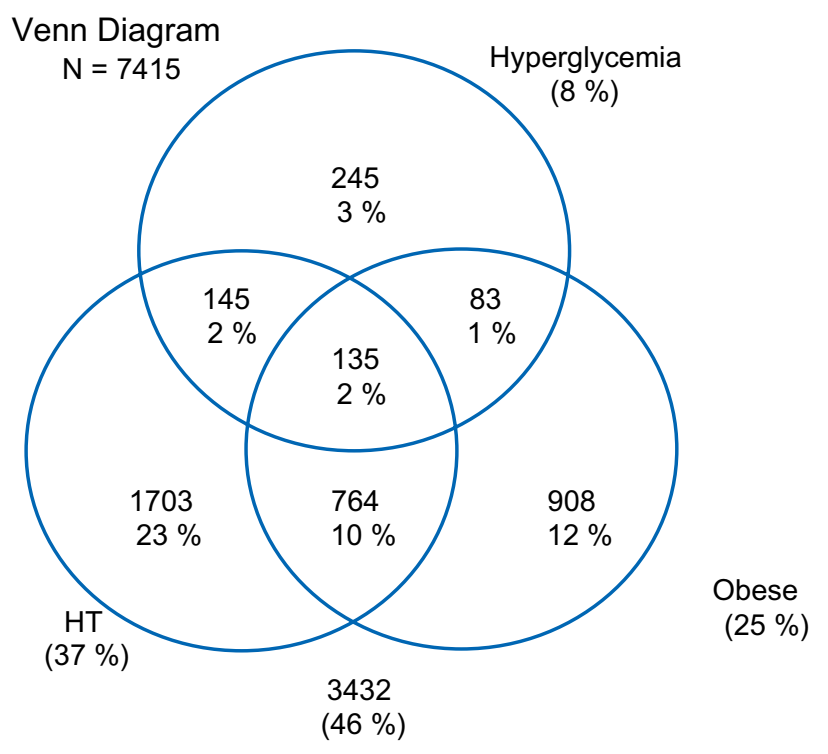

Figure 2: Overlap of hypertension, hyperglycaemia and obesity.

\section{Discussion}

In our study we found the overall prevalence of hypertension to be $27 \%$ but it increased to $58 \%$ among participants 45 years and older. In the South African National Health and Nutrition Examination Survey (SANHANES) study hypertension was found in $10.2 \%$ of participants but in $20 \%$ of those over 45 years. ${ }^{12}$ In our study there was a clinically and statistically significant trend across age groups as well as across BMI groups. Blood pressure categories also differed between males and females, mainly with regard to those with normal blood pressure (38\% in males versus $48 \%$ in females).
In the World Health Organization's Study on Global Ageing and Adult Health (SAGE) the South African national representative sample of people aged 50 years and older found hypertension ( $\geq$ $140 / 90 \mathrm{mmHg}$ or on anti-hypertensives) in $75 \%$ of males and $80 \%$ of females, making these some of the highest prevalence figures in the world. ${ }^{3}$

We found high (> $7.8 \mathrm{mmol} / \mathrm{l}$ ) random glucose levels in $8.8 \%$ of participants with $2.1 \%$ having values $>11 \mathrm{mmol} / \mathrm{l}$. There was a gender difference (males $1.6 \%$ and females $2.6 \%, p=0.013$ ). In the SANHANES study $\mathrm{HbA} 1 \mathrm{c}$ was used to diagnose diabetes and $7.9 \%$ of males and $11 \%$ of females were above this level. This makes a direct comparison with our data difficult.

Regarding subjects with multiple outcomes it is noteworthy that the overlap with obesity was rather weak. Most patients with hypertension were not obese. This would imply that focusing hypertension screening on obese subjects would certainly miss the majority of hypertensive subjects.

In the introduction we mentioned the different strategies employed for screening. In an evidence review, Durão et al..$^{21}$ concluded that the lack of evidence of clinical effectiveness of population-based screening for diabetes and hypertension should prevent low-income communities from implementing population-based screening programmes. It is clear, however, that diabetes and hypertension are not completely similar in this regard and that outcomes are dependent on the health services available to the community. In areas where clinics are not easily accessible hypertension screening may be feasible given the high probability of this condition in South Africa.

A systematic review evaluating the evidence of benefit for screening of hypertension to support the USPSTF hypertension screening recommendations concluded that ambulatory blood 
pressure measurements should be the reference standard and highlighted the fact that the failure to confirm initial elevated office-based or in our case community-based values may result in misdiagnosis and overtreatment. They also mention the possibility of using multiple home blood pressure values. ${ }^{22}$ In our setting ambulatory and home blood pressure monitoring are not viable options. There is an urgent need for more research regarding screening strategies and their outcomes in developing countries.

The motivation behind the intervention in our study was to raise awareness in the community regarding the importance of noncommunicable diseases. Our findings highlight the high prevalence of hypertension as well as the problem of follow-up testing.

\section{Limitations of the study}

The study was part of an NCD awareness campaign and therefore is by no means a random or representative sample of these communities. Random capillary glucose testing is not the ideal test for diabetes screening but was used due to easy access and will most likely be the preferred method in the proposed mass SA screening campaign. Return of participants for confirmation of diagnosis was difficult to enforce as only approximately a third of high-risk participants returned to the clinic. This provides an enormous opportunity for community-based primary care where community health care workers could potentially follow-up these people and encourage follow-up or at least do repeat testing.

Community health workers' effectiveness to screen for cardiovascular disease risk with a simple, non-invasive risk assessment instrument in Bangladesh, Guatemala, Mexico and South Africa proved to be as effective as the assessment done by health professionals. ${ }^{23}$

\section{Conclusion}

We found that $8.3 \%$ of participants had glucose values that needed repeat testing and $38.2 \%$ needed hypertension confirmation. It is unknown whether screening would lead to increased awareness and behaviour change or earlier visits to health care practitioners for diagnoses. As screening will be a part of the National Department of Health strategy to increase awareness and detection of diabetes and hypertension it would be important to link this with community-oriented primary care and to evaluate whether the desired outcomes are indeed achieved.

Acknowledgement - This study is part of the Zandspruit diabetes and hypertension control programme run by Project HOPE with the University of Pretoria as monitoring and evaluation partner. The programme is funded by the Lilly Non Communicable Disease (NCD) Program. The funder was not involved in the data collection, analyses or writing of the article. The authors would like to thank Lebohang Molete for his dedicated work as manager of the screening teams.

\section{References}

1. WHO. Health statistics and health information systems-Global Health Estimates (GHE), 2013. [cited 2016 April 25]. http://www.who. int/healthinfo/global_burden_disease/en/.

2. Found at http://www.idf.org/membership/afr/south-africa. (cited April 25, 2016).

3. Lloyd-Sherlock P, Beard J, Minicuci N, Ebrahim S, Chatterji S. Hypertension among older adults in low and middle-income countries: prevalence, awareness and control. Int J Epidemiol. 2014;43(1):11628. [http://dx.doi.org/10.1093/ije/dyt215]. [PMID:24505082].

4. American Diabetes Association. Executive summary: Standards of medical care in diabetes-2014. Diabetes Care. 2014 Jan;37 Suppl 1:S5-13. [http://dx.doi.org/10.2337/dc14-S005]. [PMID:24357214].
5. ALSiu. Screening for Abnormal Blood Glucose and Type 2 Diabetes Mellitus: U.S. Preventive Services Task Force Recommendation Statement. Ann Intern Med. 2015 163(11):861-68. [http://dx.doi. org/10.7326/M15-2345]. [PMID:26501513].

6. Schwarz PE, Li J, LindstromJ, Tuomilehto J. Tools for Predicting the Risk of Type 2 Diabetes in Daily Practice. Horm Metab Res 2009;41:86 -97. [http://dx.doi.org/10.1055/s-0028-1087203]. [PMID:19021089].

7. Christensen JO, Sandbæk A, Lauritzen T, Borch-Johnsen K. Population-based stepwise screening for unrecognised Type-2 diabetes is ineffective in general practice despite reliable algorithms. Diabetologia 2004;47:1566-73.

8. Martin E, Ruf E, Landgraf R, Hauner H, Weinauer F, Martin S. Findrisk questionnaire combined with hba1ctesting as a potential screening strategy for undiagnosed diabetes in a healthy population. Horm Metab Res 2011;43:782-87. [http://dx.doi. org/10.1055/s-0031-1286333]. [PMID:22009373].

9. Guideline Committee. The 2012SEMDSA guideline for the management of type 2 Diabetes (Revised). JEMDSA 2012;17(2)(Supplement 1): S1S95. [http://dx.doi.org/10.1080/22201009.2012.10872287].

10. Available from http://www.idf.org/sites/default/files/IDF\%20 T2DM\%20Guideline.pdf [cited 11 May 2016]

11. Tirimacco R, Tideman PA, Dunbar J, SimpsonPA, Philpot B, LaatikainenT, et al. Should capillary blood glucose measurements be used in population surveys? International Journal of Diabetes Mellitus 2010; 2: 24-27. [http://dx.doi.org/10.1016/j.ijdm.2009.12.002]

12. Marley JV, Davis S, Coleman K, Hayhow BD, Brennan G, Mein JK, et al. Point-of-care testing of capillary glucose in the exclusion and diagnosis of Diabetes in remote Australia. Med J Aust 2007;186(10):500-503.

13. Lauritzen T, Borch-Johnsen K, Davies MJ, et al. Screening for diabetes: what do the results of the ADDITION trial mean for clinical practice? Diabetes Manag. 2013;3(5):367-78. [http://dx.doi.org/10.2217/dmt.13.40].

14. Available from: http://www.uspreventiveservicestaskforce.org/Page/ Document/RecommendationStatementFinal/high-blood-pressurein-adults-screening [cited 2016, March 18].

15. Aalbers J. South African 2012 guidelines for Hypertension therapy. Cardiovasc J Afr. 2012;23(1): 53-6.

16. Available from http://www.hsrc.ac.za/uploads/pageContent/3893/ NCDs\%20STRAT\%20PLAN\%20\%20CONTENT\%208\%20april\%20 proof.pdf [cited 11 May 2016].

17. Info at https://www.lilly.co.za/ [cited 10 May 2016].

18. Info at http://thehopecentresouthafrica.blogspot.co.za/ (accessed 29 April 2016).

19. Shisana O, Labadarios D, Rehle T, Simbayi L, Zuma K, Dhansay Aet al. South African National Health and Nutrition Examination Survey 2013 (SANHANES-1). [cited 2015 April 1] Available from: http://www. hsrc.ac.za/en/research-outputs/view/6493.

20. World Health Organization. Physical status: The use and interpretation of anthropometry. Geneva: World Health Organization 1995. WHO Technical Report Series.

21. Durão S, Ajumobi O, Kredo T, Naude C, Levitt NS, Steyn K, et al. Evidence insufficient to confirm the value of population screening for Diabetes and Hypertension in low and middle-income settings. S Afr Med J 2015;105(2):98-102. [http://dx.doi.org/10.7196/samj.8819]. [PMID: 26242524].

22. Piper MA, Evans CV, Burda BU, Margolis KL, O'Connor E, Smith Net al. Screening for high blood pressure in adults: a systematic evidence review for the U.S. preventive services task force. Rockville (MD): Agency for Healthcare Research and Quality (US); 2014 Dec. Report No.: 13-05194-EF-1. U.S. Preventive Services Task Force Evidence Syntheses, formerly Systematic Evidence Reviews. PMID:25632496.

23. Gaziano TA, Abrahams-Gessel S, Denman CA, Montano CM, Khanam $M$, PuoaneT, et al. An assessment of community health workers' ability to screen for cardiovascular disease risk with a simple, non-invasive risk assessment instrument in Bangladesh, Guatemala, Mexico, and South Africa: an observational study. Lancet Glob Health. 2015 Sep;3(9):e556-63. doi:10.1016/S2214-109X(15)00143-6. Epub 2015 Jul 14. [http://www.ncbi.nlm.nih.gov/pmc/articles/PMC4795807/]. [PMID: 26187361]. 